\title{
Coordination Dynamics and Coordination Mechanism of a New Type of Anticoagulant Diethyl Citrate with $\mathrm{Ca}^{2+}$ Ions
}

\author{
Jin Han, ${ }^{1}$ Jun-Fa Xue, ${ }^{2}$ Meng Xu, ${ }^{2}$ Bao-Song Gui, ${ }^{1}$ Li Kuang, ${ }^{2}$ and Jian-Ming Ouyang ${ }^{2}$ \\ ${ }^{1}$ Department of Nephrology, The Second Hospital of Xian Jiaotong University, Xian 710004, China \\ ${ }^{2}$ Institute of Biomineralization and Lithiasis Research, Jinan University, Guangzhou 510632, China \\ Correspondence should be addressed to Bao-Song Gui; guibsdoctor@sina.com and Jian-Ming Ouyang; toyjm@jnu.edu.cn
}

Received 30 July 2013; Revised 14 November 2013; Accepted 29 November 2013

Academic Editor: Francesco Paolo Fanizzi

Copyright (c) 2013 Jin Han et al. This is an open access article distributed under the Creative Commons Attribution License, which permits unrestricted use, distribution, and reproduction in any medium, provided the original work is properly cited.

\begin{abstract}
Diethyl citrate $\left(\mathrm{Et}_{2} \mathrm{Cit}\right)$ is a new potential anticoagulant. The coordination dynamics and coordination mechanism of $\mathrm{Et}_{2} \mathrm{Cit}_{\mathrm{ith}}$ $\mathrm{Ca}^{2+}$ ions and the effect of $\mathrm{pH}$ on the complex were examined. The result was compared with that for the conventional anticoagulant sodium citrate $\left(\mathrm{Na}_{3} \mathrm{Cit}\right)$. The reaction order $(n)$ of $\mathrm{Et}_{2} \mathrm{Cit}$ and $\mathrm{Na}_{3} \mathrm{Cit}$ with $\mathrm{Ca}^{2+}$ was 2.46 and 2.44, respectively. The reaction rate constant $(k)$ was 120 and $289 \mathrm{~L} \cdot \mathrm{mol}^{-1} \cdot \mathrm{s}^{-1}$. The reverse reaction rate constant $\left(k_{\mathrm{re}}\right)$ was 0.52 and $0.15 \mathrm{~L} \cdot \mathrm{mol}^{-1} \cdot \mathrm{s}^{-1}$, respectively. It is indicated that the coordination ability of $\mathrm{Et}_{2} \mathrm{Cit}$ with $\mathrm{Ca}^{2+}$ was weaker than that of $\mathrm{Na}_{3}$ Cit. However, the dissociation rate of the calcium complex of $\mathrm{Et}_{2} \mathrm{Cit}$ was faster than that of $\mathrm{Na}_{3}$ Cit. Increased $\mathrm{pH}$ accelerated the dissociation rate of the complex and improved its anticoagulant effect. The $\mathrm{Et}_{2} \mathrm{Cit}$ complex with calcium was synthesized and characterized by elemental analysis, $\mathrm{XRD}$, FT-IR, ${ }^{1} \mathrm{H}$ NMR, and ICP. These characteristics indicated that $\mathrm{O}$ in $-\mathrm{COOH}$ and $\mathrm{C}-\mathrm{O}-\mathrm{C}$ of $\mathrm{Et}_{2} \mathrm{Cit}_{\text {it }}$ was coordinated with $\mathrm{Ca}^{2+}$ in a bidentate manner with 1:1 coordination proportion; that is, complex $\mathrm{CaEt}_{2} \mathrm{Cit}$ was formed. Given that $\mathrm{CaEt}_{2} \mathrm{Cit}_{\mathrm{released}} \mathrm{Ca}^{2+}$ more easily than $\mathrm{Na}_{3} \mathrm{Cit}$, a calcium solution was not needed in intravenous infusions using $\mathrm{Et}_{2} \mathrm{Cit}$ as anticoagulant unlike using $\mathrm{Na}_{3}$ Cit. Consequently, hypocalcemia and hypercalcemia were avoided.
\end{abstract}

\section{Introduction}

An anticoagulant must be added to dialysates to prevent blood solidification in vitro (in a dialysis machine). Sodium citrate $\left(\mathrm{Na}_{3} \mathrm{Cit}\right)$ is an important anticoagulant used in clinical settings [1-3]. However, using $\mathrm{Na}_{3} \mathrm{Cit}$ as an anticoagulant easily causes hypocalcemia and hypercalcemia $[4,5]$ because of the strong chelating ability of $\mathrm{Na}_{3} \mathrm{Cit}$ with $\mathrm{Ca}^{2+}$ ions. Given this ability, the dissociation metabolism of the formed chelate CaCit in vivo takes $30 \mathrm{~min}$. Using $\mathrm{Na}_{3} \mathrm{Cit}$ also negatively affects the maintenance of coagulation stability of high-risk hemorrhage patients in vivo, which easily causes complications such as hypocalcemia during or after dialysis.

Our group has previously synthesized a new anticoagulant [6], namely, diethyl citrate $\left(\mathrm{Et}_{2} \mathrm{Cit}\right)$. The anticoagulant mechanism of $\mathrm{Et}_{2} \mathrm{Cit}$ is based on the formation of $\mathrm{Ca}^{2+}$ with $\mathrm{Et}_{2} \mathrm{Cit}$. This formation decreases the $\mathrm{Ca}^{2+}$ concentration in blood and inhibits prothrombin conversion into thrombin, thereby influencing the anticoagulant effect. The large steric effect of $\mathrm{Et}_{2}$ Cit weakens the coordination of $\mathrm{Ca}^{2+}$ ion compared with that of $\mathrm{Na}_{3} \mathrm{Cit}$. Therefore, hypocalcemia and hypercalcemia can be avoided using $\mathrm{Et}_{2} \mathrm{Cit}$ as anticoagulant [7]. The frequency of blood gas analyses can also be lessened by repeatedly taking the venous blood of patients to monitor serum calcium levels, which can help relieve the pain of patients and the workload of nurses.

The stability of the complex of $\mathrm{Et}_{2} \mathrm{Cit}$ with $\mathrm{Ca}^{2+}$ $\left(\mathrm{CaEt}_{2} \mathrm{Cit}\right)$ is reportedly weaker than that of $\mathrm{CaCit}$ [8]. At pH 7.4 and $37^{\circ} \mathrm{C}$, the stability constants $\left(K_{s}^{\prime}\right.$ 's) are 1988 for CaCit and 231 for $\mathrm{CaEt}_{2} \mathrm{Cit}$. However, several problems remain unsolved when $\mathrm{Et}_{2} \mathrm{Cit}$ is used as an anticoagulant. These problems include the reaction kinetics of $\mathrm{Et}_{2} \mathrm{Cit}$ with $\mathrm{Ca}^{2+}$ and coordination reaction mechanisms, as well as the composition and characterization of the complex. Accordingly, the coordination dynamics of $\mathrm{Et}_{2} \mathrm{Cit}$ and $\mathrm{Na}_{3} \mathrm{Cit}$ with $\mathrm{Ca}^{2+}$, as well as the influencing factors, were studied. The underlying coordination principle was also proposed. 


\section{Materials and Methods}

2.1. Instruments and Reagents. The instruments used were as follows: $\mathrm{CHN}-\mathrm{O}$ - rapid type element analyzer (Foss-Heraeus Company), Bruker AM 500 nuclear magnetic resonance (NMR) spectrometer (with $\mathrm{CDCl}_{3}$ as solvent and TMS as internal standard), Nicolet-170 SX type FT-IR spectrometer, $D / \max 2400$ (Rigaku) X-ray diffractometer, inductively coupled plasma emission spectrometry (ICP) system (PE Company, USA), PHS-3C pH meter (Shanghai Precision \& Scientific Instrument Co., Ltd., China), and sodium chloride injection system (Wuhan Binhu Double-Crane Pharmaceutical Co., Ltd., China).

All chemical reagents used were of analytical grade. $\mathrm{Et}_{2} \mathrm{Cit}$ was prepared in our laboratory (99.3\% purity) [6].

\subsection{Experimental Methods}

2.2.1. Reaction Rate Constants of Et $t_{2}$ Cit and $\mathrm{Na}_{3}$ Cit with $\mathrm{Ca}^{2+}$. $\mathrm{CaCl}_{2}$ and $\mathrm{Et}_{2} \mathrm{Cit}$ solutions $(2.0 \mathrm{mmol} / \mathrm{L})$ were prepared and mixed. A calcium-ion-selective electrode was used to determine the change in electrode potential of the mixed solution with reaction time at $\mathrm{pH} 7.4$ and $37^{\circ} \mathrm{C}$ under stirring. The result was then compared with that of $\mathrm{Na}_{3} \mathrm{Cit}$.

The linear regression equation of the calcium ionselective electrode was $y=29 x+69$ (where $y$ is the electrode potential and $x$ is $-\mathrm{p}\left(\mathrm{Ca}^{2+}\right)$. The concentration of $\mathrm{Ca}^{2+}\left[c\left(\mathrm{Ca}^{2+}\right)\right]$ at $t$ time was also calculated. Given that $\mathrm{CaCl}_{2}$ was mixed with $\mathrm{Na}_{3} \mathrm{Cit}$ or $\mathrm{Et}_{2} \mathrm{Cit}(1: 1)$ and that the reaction of $\mathrm{Ca}^{2+}$ with $\mathrm{Na}_{3}$ Cit or $\mathrm{Et}_{2}$ Cit was equal in solution [7], the following reaction rate equation can be established using $r$ to represent the reaction rate:

$$
r=k c^{n}
$$

where $k$ is the reaction rate constant and $n$ is the reaction order. Assuming that $x$ is the amount of $\mathrm{Ca}^{2+}$ substance concentration that disappeared at $t$ time, that is, $x=a-c$ $\left(\mathrm{Ca}^{2+}\right)$, the following can be obtained by arranging formula (1):

$$
r=-\frac{d c}{d t}=-\frac{d(a-x)}{d t}=\frac{d x}{d t}=k(a-x)^{n} .
$$

After logarithm on both sides we get

$$
\begin{aligned}
\log r & =\log \left(-\frac{d(a-x)}{d t}\right)=\log k+n \log (a-x) \\
& =\log k+n \log c .
\end{aligned}
$$

From the plot of $x$ versus $t$, we can calculate the tangent slope of the curve $d x / d t$, which is the reaction rate of various points. Formula (3) shows a linear relationship between $\log r$ and $\log c\left(\mathrm{Ca}^{2+}\right)$. In the diagram of $\log r$ on $\log c\left(\mathrm{Ca}^{2+}\right)$, the slope of the straight line is the reaction order $n$, whereas the intercept is $\log k$.

2.2.2. Effect of $\mathrm{pH}$ on Reaction Rate. The $\mathrm{pH}$ of the system was adjusted to $6.0,7.4$, and 8.0. Then, the effect of $\mathrm{pH}$ on $k$ and $n$ was determined.

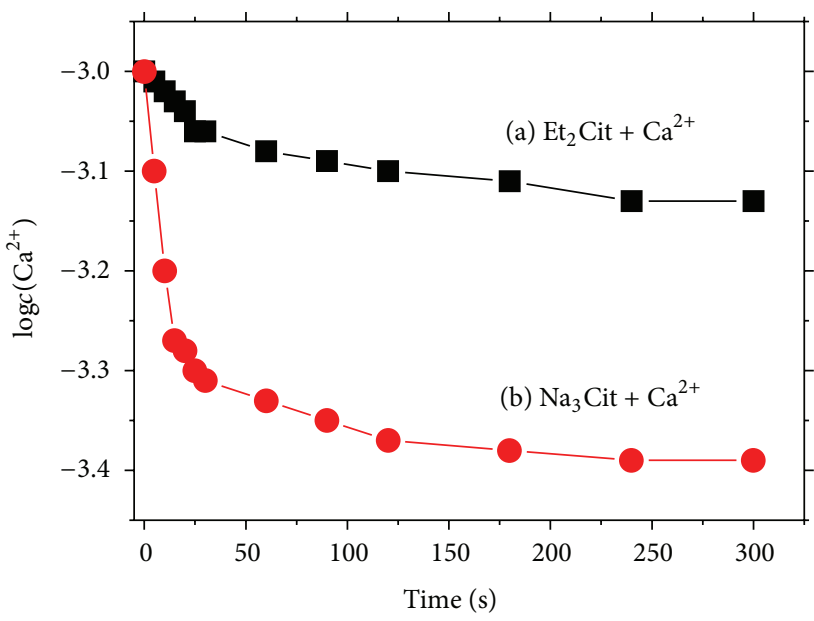

Figure 1: Changes in $\mathrm{Ca}^{2+}$ concentration with reaction time in different systems: (a) $\mathrm{Et}_{2} \mathrm{Cit}-\mathrm{Ca}^{2+}$ system and (b) $\mathrm{Na}_{3} \mathrm{Cit}-\mathrm{Ca}^{2+}$ system.

2.2.3. Synthesis of Diethyl Citrate Calcium Complex Crystal. About $1.665 \mathrm{~g}(15 \mathrm{mmol})$ of anhydrous $\mathrm{CaCl}_{2}$ was completely dissolved in water. Then, $1.241 \mathrm{~g}(5 \mathrm{mmol})$ of $\mathrm{Et}_{2} \mathrm{Cit}$ was slowly trickled under stirring. The $\mathrm{pH}$ was adjusted to 7.0 after obtaining a colorless and transparent solution. The solution was sealed with a plastic wrap having holes and then placed in an oven at $37^{\circ} \mathrm{C}$ for slow volatilization and crystallization. The precipitated colorless, needle-like crystals were filtered, washed with anhydrous ethanol, dried, and characterized. The methods of characterization included elemental analysis, $\mathrm{X}$-ray powder diffraction (XRD), Fourier-transform infrared spectroscopy (FT-IR), ${ }^{1} \mathrm{H}$ NMR, and ICP.

\section{Results and Discussion}

3.1. Reaction Rate Equation of $\mathrm{Et}_{2} \mathrm{Cit}$ and $\mathrm{Na}_{3} \mathrm{Cit}$ with $\mathrm{Ca}^{2+}$. The change in concentration of free $\mathrm{Ca}^{2+}$ ion $\left[c\left(\mathrm{Ca}^{2+}\right)\right]$ with $t$ in reaction system of $\mathrm{Et}_{2} \mathrm{Cit}$ and $\mathrm{Na}_{3}$ Cit with $\mathrm{CaCl}_{2}$ is shown in Figure 1. A rapid decrease in $c\left(\mathrm{Ca}^{2+}\right)$ was observed with prolonged $t$ from $0 \mathrm{~s}$ to $30 \mathrm{~s}$. This finding indicated that $\mathrm{Et}_{2} \mathrm{Cit}$ or $\mathrm{Na}_{3}$ Cit was rapidly coordinated with $\mathrm{Ca}^{2+}$. At $t=30 \mathrm{~s}$, $c\left(\mathrm{Ca}^{2+}\right)$ decreased from $1.0 \mathrm{mmol} / \mathrm{L}$ to $0.49 \mathrm{mmol} / \mathrm{L}$ in the $\mathrm{Na}_{3}$ Cit system and from $1.0 \mathrm{mmol} / \mathrm{L}$ to $0.87 \mathrm{mmol} / \mathrm{L}$ in the $\mathrm{Et}_{2}$ Cit system. $c\left(\mathrm{Ca}^{2+}\right)$ slowly decreased when $t>120 \mathrm{~s}$, indicating that the system was in a dynamic equilibrium of complexation dissociation.

The tangent slope $(d x / d t)$ of points on the curve, that is, the reaction rate $r$ of each point formula (2), can be obtained according to Figure 1. In the diagram of $\log r$ versus $\log c\left(\mathrm{Ca}^{2+}\right)$ (Figure 2), the slope of the line was the reaction order $n$ (formula (3)). The intercept of the line was $\log k$ in Figure 2, as shown in the following:

$\mathrm{Et}_{2}$ Cit-Ca system $: n=2.46 ; \log k=2.06$, so $k=120$;

$\mathrm{Na}_{3}$ Cit-Ca system: $n=2.44 ; \log k=2.46$, so $k=289$. 


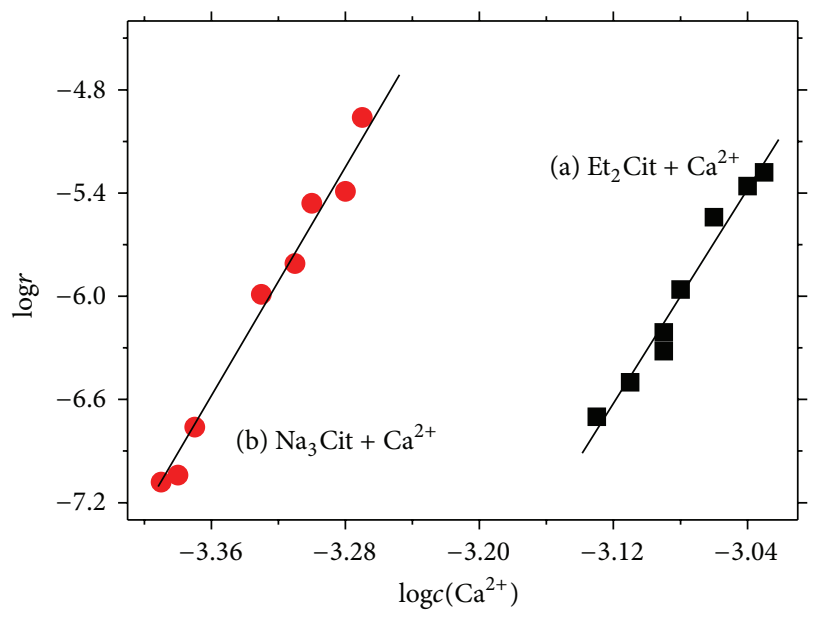

Figure 2: Plots of $\log r-\log c\left(\mathrm{Ca}^{2+}\right)$ in different systems: (a) $\mathrm{Et}_{2} \mathrm{Cit}-$ $\mathrm{Ca}^{2+}$ system and (b) $\mathrm{Na}_{3} \mathrm{Cit}-\mathrm{Ca}^{2+}$ system.

The reaction rate equations of $\mathrm{Et}_{2} \mathrm{Cit}$ and $\mathrm{Na}_{3} \mathrm{Cit}$ with $\mathrm{Ca}^{2+}$ were as follows:

$$
\begin{aligned}
& \mathrm{Et}_{2} \text { Cit-Ca system }: r=k a^{2.46}=120 a^{2.46}, \\
& \mathrm{Na}_{3} \text { Cit-Ca system }: r=k a^{2.44}=289 a^{2.44} .
\end{aligned}
$$

Given that $k$ can directly reflect the reaction rate, (5) shown that the complexation rate of $\mathrm{Na}_{3} \mathrm{Cit}$ with $\mathrm{Ca}^{2+}$ was faster than that of $\mathrm{Et}_{2} \mathrm{Cit}$.

The anticoagulant mechanism of $\mathrm{Na}_{3} \mathrm{Cit}$ and $\mathrm{Et}_{2} \mathrm{Cit}$ was based on the combination of calcium ion $\left(\mathrm{Ca}^{2+}\right)$ in serum, as well as the reduced concentration of free $\mathrm{Ca}^{2+}$ in plasma that disturbed the blood clotting process from reaching the anticoagulation effect in vitro [9-11]. However, the strong coordination ability of $\mathrm{Na}_{3} \mathrm{Cit}$, particularly as an anticoagulant, can coordinate a large number of $\mathrm{Ca}^{2+}$ ions in the blood. This phenomenon can lead to the low serum concentration of calcium in patients, as well as to hypocalcemia and all kinds of complications [12-15]. Therefore, calcium is needed to be replenished in the anticoagulation process of $\mathrm{Na}_{3}$ Cit [16]. Meanwhile, calcium citrate [CaCit] can dissociate during the metabolism and release $\mathrm{Ca}^{2+}$ after entering the body in the dialysis process. Additionally, hypercalcemia easily ensued in patients with presupplementary $\mathrm{Ca}^{2+}$. Therefore, the incidence of hypocalcemia and hypercalcemia can be reduced if we can reduce the coordination ability of anticoagulant.

The reaction rate was equal to the inverse reaction rate when the reaction reached equilibrium, as shown in the following:

$$
k(a-x)^{n}=k_{\mathrm{re}} x^{n} .
$$

The above equation can be written as follows [17]:

$$
\frac{x^{n}}{(a-x)^{n}}=\frac{k}{k_{\mathrm{re}}}=K_{s},
$$

where $k$ is the reaction rate constant, $k_{\mathrm{re}}$ is the inverse reaction rate constant, and $K_{s}$ is the complex stability constant.
In a previous article [8], the $K_{s}$ values of $\mathrm{CaEt}_{2} \mathrm{Cit}$ and $\mathrm{CaCit}$ were 231 and 1988 at $\mathrm{pH} 7.4$ and $37^{\circ} \mathrm{C}$, respectively, and the $k$ values in the coordination reaction of $\mathrm{Et}_{2} \mathrm{Cit}$ and $\mathrm{Na}_{3}$ Cit with $\mathrm{Ca}^{2+}$ were 120 and $289 \mathrm{~L} \cdot \mathrm{mol}^{-1} \cdot \mathrm{s}^{-1}$, respectively. According to (7), $k_{\text {re }}$ of $\mathrm{Et}_{2} \mathrm{Cit}$ and $\mathrm{Na}_{3} \mathrm{Cit}$ with $\mathrm{Ca}^{2+}$ in the coordination reaction were 0.52 and $0.15 \mathrm{~L} \cdot \mathrm{mol}^{-1} \cdot \mathrm{s}^{-1}$, respectively. Thus, the rate of decomposition and release of $\mathrm{Ca}^{2+}$ was faster for $\mathrm{CaEt}_{2} \mathrm{Cit}$ than for CaCit. The above results indicated that $\mathrm{Et}_{2} \mathrm{Cit}$ can complex with $\mathrm{Ca}^{2+}$ and reduce the free $\mathrm{Ca}^{2+}$ concentration during anticoagulation; thus, anticoagulation can be achieved. Meanwhile, the complexing ability of $\mathrm{Et}_{2} \mathrm{Cit}$ with $\mathrm{Ca}^{2+}$ was weaker than that of $\mathrm{Na}_{3} \mathrm{Cit}$. After $\mathrm{Et}_{2} \mathrm{Cit}$ coordinated with $\mathrm{Ca}^{2+}$, the $\mathrm{Ca}^{2+}$ releasing rate of $\mathrm{CaEt}_{2} \mathrm{Cit}$ was faster than that of CaCit. Therefore, the occurrence of hypocalcemia in patients can be avoided. Moreover, only a small amount of calcium or none at all was needed using $\mathrm{Et}_{2} \mathrm{Cit}$ as anticoagulant during dialysis unlike using $\mathrm{Na}_{3}$ Cit. Thus, the occurrence of hypercalcemia can be avoided using $\mathrm{Et}_{2} \mathrm{Cit}$ as an anticoagulant.

3.2. Effect of pH on Reaction Rate. At present, the main dialysates in clinical practice are bicarbonate and acetic dialysis liquid. The $\mathrm{pH}$ of acetate dialysate is generally controlled to remain at 6.0 to 7.2 [18]. In [19], the $\mathrm{pH}$ range of the dialysate is 5.3-8.2. At the entrance of the dialysis machine, the $\mathrm{pH}$ of a patient's whole blood was between 7.15 and 7.4, whereas the $\mathrm{pH}$ of the exports of the dialysis machine was between 6.2 and 7.4 .

In the dialysis process, the $\mathrm{pH}$ values of different dialysates varied. The acidities of different anticoagulants also differed. Therefore, the $\mathrm{pH}$ of blood in the dialysis process also changed. Considering that $\mathrm{Na}_{3} \mathrm{Cit}$ was a strong base-weak acid salt, $1 \mathrm{~mol}$ of $\mathrm{Na}_{3}$ Cit contained $3 \mathrm{~mol}$ of carboxylate $\left(\mathrm{COO}^{-}\right)$, wherein $\mathrm{Na}_{3} \mathrm{Cit}$ was alkaline. Therefore, when $\mathrm{Na}_{3}$ Cit was used as an anticoagulant, the blood $\mathrm{pH}$ decreased and metabolic alkalosis likely ensued.

Considering that one $\mathrm{Et}_{2}$ Cit molecule only had one $-\mathrm{COO}^{-}$, the possibility of causing alkalosis was significantly reduced when $\mathrm{Et}_{2} \mathrm{Cit}$ was used as anticoagulant. With increased $\mathrm{pH}$ from 6.0 to 8.0 , free $c\left(\mathrm{Ca}^{2+}\right)$ decreased faster in the system (Figure 3 ) because increased $\mathrm{pH}$ benefited the ionization of $-\mathrm{OH}$ and $-\mathrm{COOH}$ of $\mathrm{Et}_{2} \mathrm{Cit}$ or $\mathrm{Na}_{3} \mathrm{Cit}$, which in turn benefited the coordination with $\mathrm{Ca}^{2+}$.

Table 1 shows the reaction rate constants $k$ of $\mathrm{Et}_{2} \mathrm{Cit}$ and $\mathrm{Na}_{3}$ Cit with $\mathrm{CaCl}_{2}$, as well as the complex dissociation rate $k_{\text {re }}$ when the $\mathrm{pH}$ values of the system were $6.0,7.4$, and 8.0. The reaction rate and dissociation rate of the complex were found to accelerate with increased $\mathrm{pH}$. The reaction rate of $\mathrm{Et}_{2} \mathrm{Cit}$ and $\mathrm{Na}_{3}$ Cit with $\mathrm{CaCl}_{2}$ was influenced by $\mathrm{pH}$ because $\mathrm{H}^{+}$inhibits the ionization of the active $\mathrm{H}$ of $-\mathrm{COOH}$ in $\mathrm{Et}_{2} \mathrm{Cit}$ molecule, as well as changing the course of coordination reaction. Thus, the reaction rate constant and reaction order changed.

Within $\mathrm{pH}$ 6.0-8.0, the $\mathrm{pH}$ increase accelerated the dissociation rate of the complex. With increased $\mathrm{pH}$ from 6.0 to 8.0, $k_{\text {re }}$ of the $\mathrm{Et}_{2} \mathrm{Cit}-\mathrm{CaCl}_{2}$ system increased from 0.04 to 19.8 , whereas $k_{\text {re }}$ of the $\mathrm{Na}_{3} \mathrm{Cit}-\mathrm{CaCl}_{2}$ system increased from 0.03 to 6.79. The dissociation rate of the complex for the coordination of $\mathrm{Et}_{2} \mathrm{Cit}$ and $\mathrm{Na}_{3} \mathrm{Cit}$ with calcium under an alkaline 


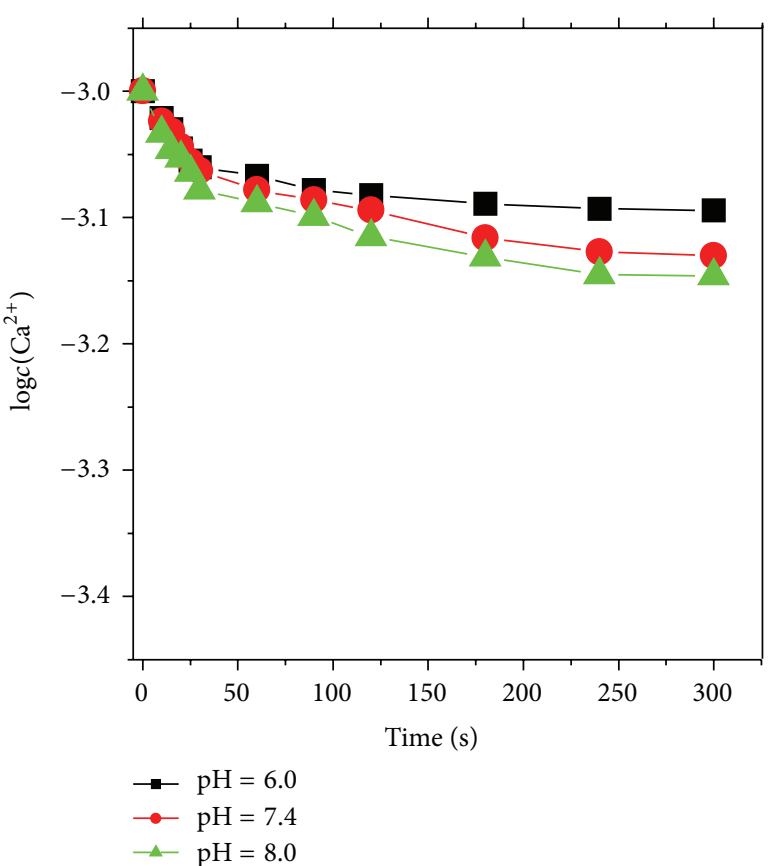

(a)

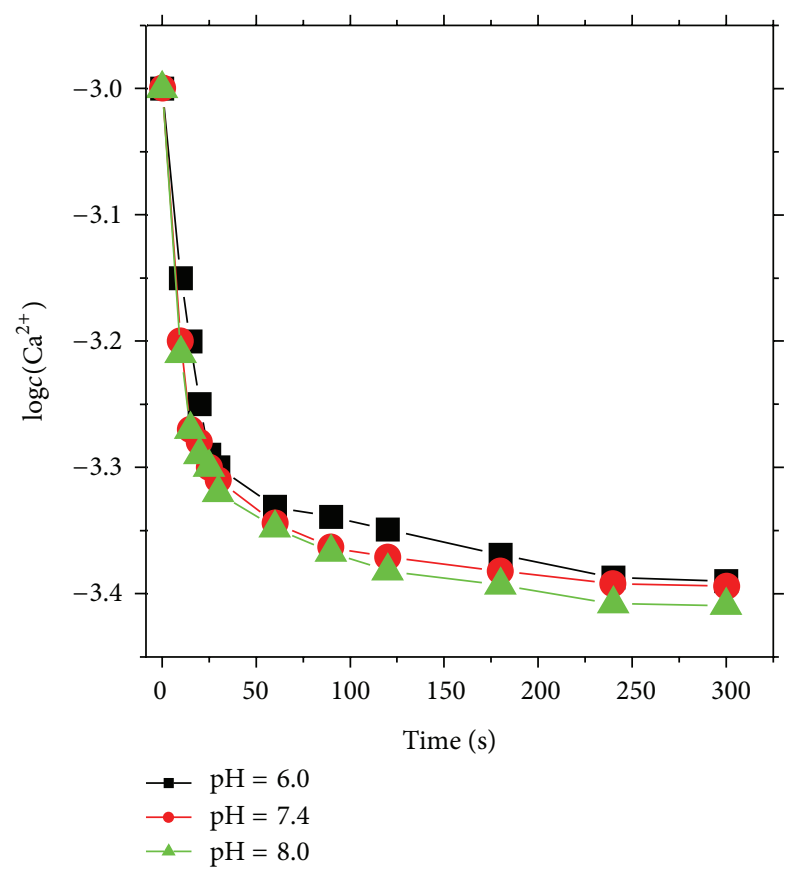

(b)

FIgure 3: Plots of concentration change of free $\mathrm{Ca}^{2+}$ ions with reaction time under different $\mathrm{pH}$ conditions: (a) $\mathrm{Et}_{2} \mathrm{Cit}$ and (b) $\mathrm{Na}_{3} \mathrm{Cit}$.

TABLE 1: Reaction rate constant and reaction order of $\mathrm{Et}_{2} \mathrm{Cit}$ and $\mathrm{Na}_{3} \mathrm{Cit}$ with $\mathrm{Ca}^{2+}$ ions.

\begin{tabular}{|c|c|c|c|}
\hline $\mathrm{pH}$ & 6.0 & 7.4 & 8.0 \\
\hline \multicolumn{4}{|l|}{$\mathrm{Et}_{2} \mathrm{Cit}-\mathrm{CaCl}_{2}$ system } \\
\hline reaction order $(n)$ & 2.03 & 2.46 & 2.73 \\
\hline stability constants $\left(K_{s}\right)$ & $10^{0.93}$ & $10^{2.06}$ & $10^{3.06}$ \\
\hline rate constant $(k) / \mathrm{L} \cdot \mathrm{mol}^{-1} \cdot \mathrm{s}^{-1}$ & 9 & 120 & 4571 \\
\hline reverse reaction rate constant $\left(k_{\mathrm{re}}\right) / \mathrm{L} \cdot \mathrm{mol}^{-1} \cdot \mathrm{s}^{-1}$ & 0.04 & 0.52 & 19.80 \\
\hline \multicolumn{4}{|l|}{$\mathrm{Na}_{3} \mathrm{Cit}-\mathrm{CaCl}_{2}$ system } \\
\hline reaction order $(n)$ & 2.16 & 2.44 & 3.0 \\
\hline$K_{s}$ & $10^{1.98}$ & $10^{2.46}$ & $10^{4.83}$ \\
\hline$k / \mathrm{L} \cdot \mathrm{mol}^{-1} \cdot \mathrm{s}^{-1}$ & 60 & 289 & 13489 \\
\hline$k_{\mathrm{re}} / \mathrm{L} \cdot \mathrm{mol}^{-1} \cdot \mathrm{s}^{-1}$ & 0.03 & 0.15 & 6.79 \\
\hline
\end{tabular}

condition was faster than that under an acidic condition. Therefore, the $\mathrm{pH}$ increase of anticoagulants such as $\mathrm{Et}_{2} \mathrm{Cit}$ and $\mathrm{Na}_{3} \mathrm{Cit}$ and dialysis under alkaline conditions achieved the purpose of anticoagulation and avoided the occurrence of dialysis acidosis, thereby improving the survival rate and quality of life.

\subsection{Research on $\mathrm{Et}_{2}$ Cit and $\mathrm{Ca}$ Complexes}

3.3.1. Elemental Analysis and Ca Content as Determined by ICP. To further study the coordination of $\mathrm{Et}_{2} \mathrm{Cit}$ with $\mathrm{Ca}^{2+}$, the complex of $\mathrm{Et}_{2} \mathrm{Cit}$ with $\mathrm{Ca}^{2+}$ was synthesized. Its composition was analyzed using elemental analysis and ICP, and the results are shown in Table 2. $\mathrm{Et}_{2}$ Cit was found to form the complex of $\mathrm{CaEt}_{2}$ Cit with $\mathrm{Ca}^{2+}$ in $1: 1$ coordination ratio.
TABLE 2: Elemental analysis data and Ca content measured by the ICP of complex $\mathrm{CaEt}_{2} \mathrm{Cit}$.

\begin{tabular}{lccc}
\hline & $\mathrm{C} \%$ & $\mathrm{H} \%$ & $\mathrm{Ca} \%$ \\
\hline EA results & $41.55(41.64)^{*}$ & $5.73(5.55)$ & - \\
ICP result & - & - & $13.68(13.93)$ \\
\hline
\end{tabular}

${ }^{*}$ The value in bracket was theoretical value, which is calculated according to the formula of complex $\mathrm{CaEt}_{2} \mathrm{Cit}$.

Therefore, the experimental value was consistent with the theoretical value.

3.3.2. XRD Analysis. Figure 4 is the XRD pattern of $\mathrm{CaCl}_{2}$ and $\mathrm{CaEt}_{2} \mathrm{Cit}$ crystals. The diffraction peaks of $\mathrm{CaCl}_{2}$ appeared at $d=5.97,2.78,3.03,4.28$, and $2.90 \AA$ (Figure 4(a)), 
TABLE 3: Wavenumber of the main absorption peaks of FT-IR spectra of $\mathrm{Et}_{2} \mathrm{Cit}$ and its complex $\mathrm{CaEt}_{2} \mathrm{Cit}$.

\begin{tabular}{lcccc}
\hline $\mathrm{Et}_{2} \mathrm{Cit} / \mathrm{cm}^{-1}$ & $3480(\mathrm{OH})^{*}$ & $2986\left(\mathrm{CH}_{2}, \mathrm{CH}_{3}\right)$ & $1732(\mathrm{O}-\mathrm{C}=\mathrm{O})$ & $1100(\mathrm{C}-\mathrm{O}-\mathrm{C})$ \\
$\mathrm{CaEt}_{2} \mathrm{Cit} / \mathrm{cm}^{-1}$ & $3430(\mathrm{OH})$ & $2982\left(\mathrm{CH}_{2},-\mathrm{CH}_{3}\right)$ & $1709,1624(\mathrm{O}-\mathrm{C}=\mathrm{O})$ & $1081,1041(\mathrm{C}-\mathrm{O}-\mathrm{C})$ \\
\hline
\end{tabular}

TABLE 4: Absorption peak section and its assignment of the ${ }^{1} \mathrm{H}$ NMR spectra of $\mathrm{Et}_{2} \mathrm{Cit}_{\text {and }} \mathrm{CaEt}_{2} \mathrm{Cit}_{\text {. }}$

\begin{tabular}{lllll}
\hline $\mathrm{Et}_{2} \mathrm{Cit} / \mathrm{ppm}$ & $1.24 \sim 1.31\left(-\mathrm{CH}_{3}\right)$ & $2.80-2.97\left(-\mathrm{CH}_{2} \mathrm{CO}\right)$ & $4.13 \sim 4.30\left(-\mathrm{OCH}_{2}\right)$ & $7.26,6.28(-\mathrm{OH})$ \\
$\mathrm{CaEt}_{2} \mathrm{Cit} / \mathrm{ppm}$ & $1.22 \sim 1.28\left(-\mathrm{CH}_{3}\right)$ & $2.77-2.98\left(-\mathrm{CH}_{2} \mathrm{CO}\right)$ & $4.12 \sim 4.17\left(-\mathrm{OCH}_{2}\right)$ \\
\hline
\end{tabular}

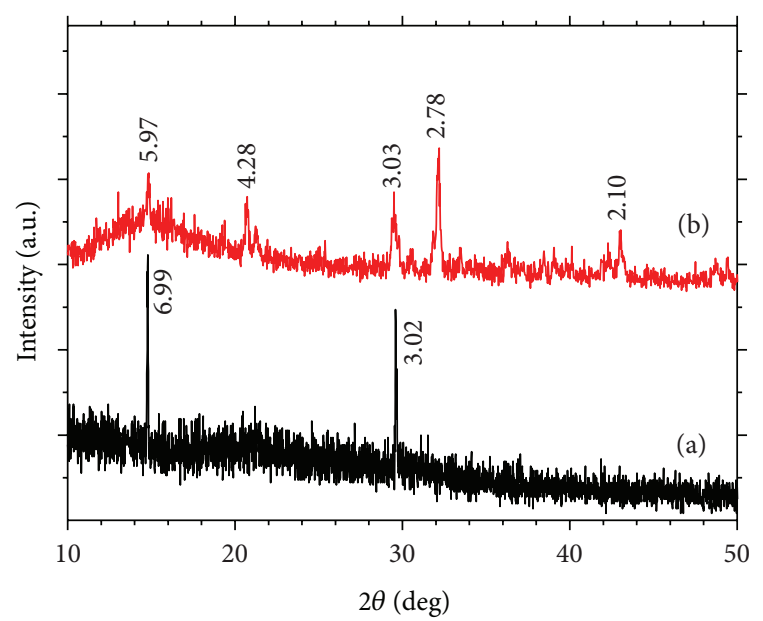

FIGURE 4: XRD patterns of $\mathrm{CaEt}_{2} \mathrm{Cit}$ and $\mathrm{CaCl}_{2}$ : (a) $\mathrm{CaEt}_{2} \mathrm{Cit}$ and (b) $\mathrm{CaCl}_{2}$.

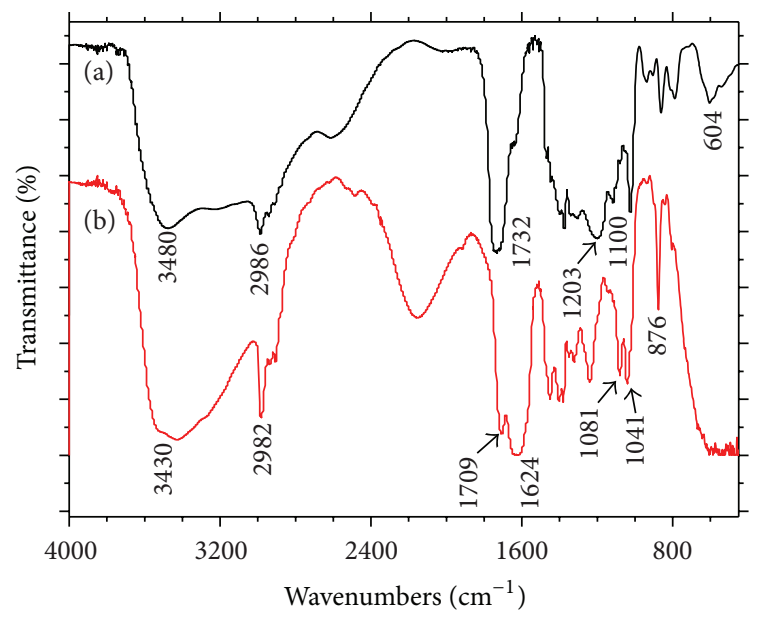

Figure 5: FT-IR spectra of $\mathrm{Et}_{2}$ Cit and its complex $\mathrm{CaEt}_{2} \mathrm{Cit}$ : (a) $\mathrm{Et}_{2} \mathrm{Cit}$ and (b) $\mathrm{CaEt}_{2} \mathrm{Cit}$.

whereas the diffraction peaks of the complex appeared at $d=6.99$ and $3.02 \AA$.

3.3.3. FT-IR Analysis. The FT-IR spectra of $\mathrm{Et}_{2} \mathrm{Cit}$ and $\mathrm{CaEt}_{2} \mathrm{Cit}$ complex are shown in Figure 5. The wavenumbers of the main absorption peaks are shown in Table 3 [20].

(1) The peak at $3430 \mathrm{~cm}^{-1}$ was due to the stretching vibration of the hydroxyl group in the $\mathrm{CaEt}_{2} \mathrm{Cit}$ complex, which red shifted by approximately $50 \mathrm{~cm}^{-1}$ more than that of $\mathrm{Et}_{2} \mathrm{Cit}\left(3480 \mathrm{~cm}^{-1}\right)$, indicating a hydrogen bond.

(2) The carbonyl absorption peak $(\mathrm{C}=\mathrm{O})$ of $\mathrm{CaEt}_{2} \mathrm{Cit}$ split into two peaks, which were 1709 and $1624 \mathrm{~cm}^{-1}$, respectively, indicating two different coordination environments in carbonyl. The position of both peaks red-shifted by approximately more than 30 and $110 \mathrm{~cm}^{-1}$ compared with the carbonyl absorption peaks of $\mathrm{Et}_{2} \mathrm{Cit}$ at $1736 \mathrm{~cm}^{-1}$. This finding indicated that the carbonyl of $\mathrm{Et}_{2} \mathrm{Cit}$ was coordinated with the calcium ions and was consistent with the change in the carbonyl characteristic absorption peak before and after coordination, as reported in [20].

(3) The absorption peak of the symmetric stretching vibrations of $(\mathrm{C}-\mathrm{O}-\mathrm{C})$ in $\mathrm{C}-\mathrm{O}-\mathrm{C}$ of $\mathrm{Et}_{2}$ Cit was at $1100 \mathrm{~cm}^{-1}$. However, the peak split into two in the complex, that is, at 1081 and $1041 \mathrm{~cm}^{-1}$, respectively. This phenomenon was ascribed to one of the three $\mathrm{C}-\mathrm{O}-\mathrm{C}$ groups of the $\mathrm{Et}_{2} \mathrm{Cit}$ molecular complex with $\mathrm{Ca}^{2+}$, in which $\mathrm{C}-\mathrm{O}-\mathrm{C}$ absorption was bimodal and red shifted.

(4) The peak at $2982 \mathrm{~cm}^{-1}$ was the absorption peak of the methyl hydrocarbon of $\mathrm{CaEt}_{2} \mathrm{Cit}$. It did not significantly change compared with the absorption peak of $\mathrm{Et}_{2}$ Cit methyl hydrocarbon $\left(2986 \mathrm{~cm}^{-1}\right)$.

3.3.4. ${ }^{1} \mathrm{H} N M R$. The ${ }^{1} \mathrm{H}$ NMR spectra of $\mathrm{Et}_{2} \mathrm{Cit}$ and $\mathrm{CaEt}_{2} \mathrm{Cit}$ were studied using $\mathrm{CDCl}_{3}$ as a solvent, and the results are shown in Figure 6. The absorption peaks of ${ }^{1} \mathrm{H}$ NMR are shown in Table 4.

(1) The proton peaks of the ligand at $\delta=7.26$ and $6.28 \mathrm{ppm}$ disappeared, indicating that $-\mathrm{COOH}$ participated in the coordination reaction. Meanwhile, the hydrogen in - $\mathrm{OH}$ group is very active; it can be easily dissociated and be partially or entirely substituted by deuterium in $\mathrm{CDCl}_{3}$ solution.

(2) At $2.70 \mathrm{ppm}$ to $3.0 \mathrm{ppm}$, the two groups of $\mathrm{Et}_{2} \mathrm{Cit}$ quartets were $-\mathrm{CH}_{2} \mathrm{C}=\mathrm{O}$ (Figure 6(b)). $-\mathrm{CH}_{2} \mathrm{C}=\mathrm{O}$ groups occurred in different chemical environments, that is, $1,3-\mathrm{Et}_{2} \mathrm{Cit}$ and $1,5-\mathrm{Et}_{2} \mathrm{Cit}$. The physical and chemical properties of the two isomers were very similar, so the two peaks did not significantly differ. After $\mathrm{CaEt}_{2} \mathrm{Cit}$ was generated, the chemical environment of $\mathrm{Et}_{2} \mathrm{Cit}$ changed and resulted in obvious dispersion 


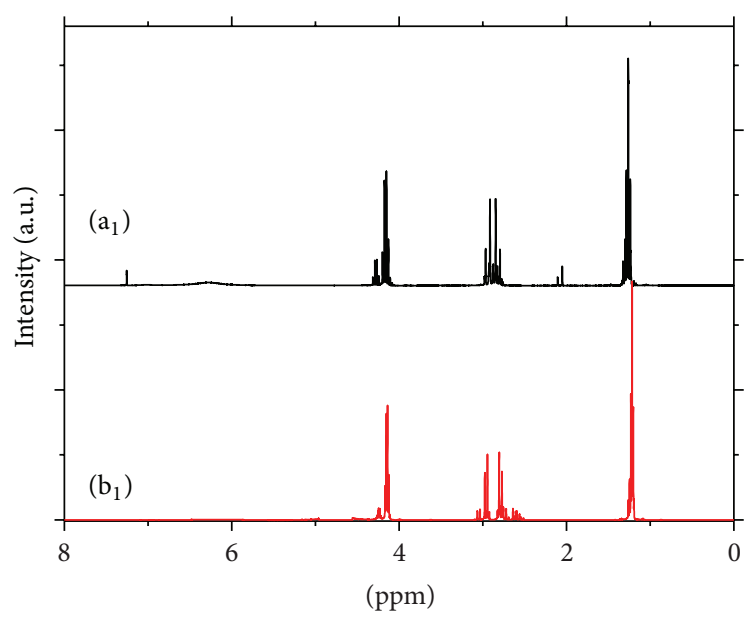

(a)

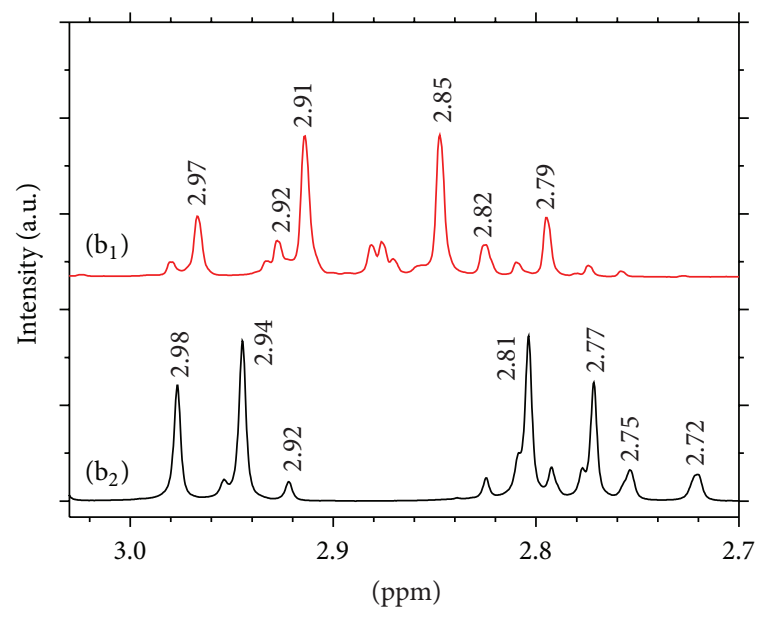

(b)

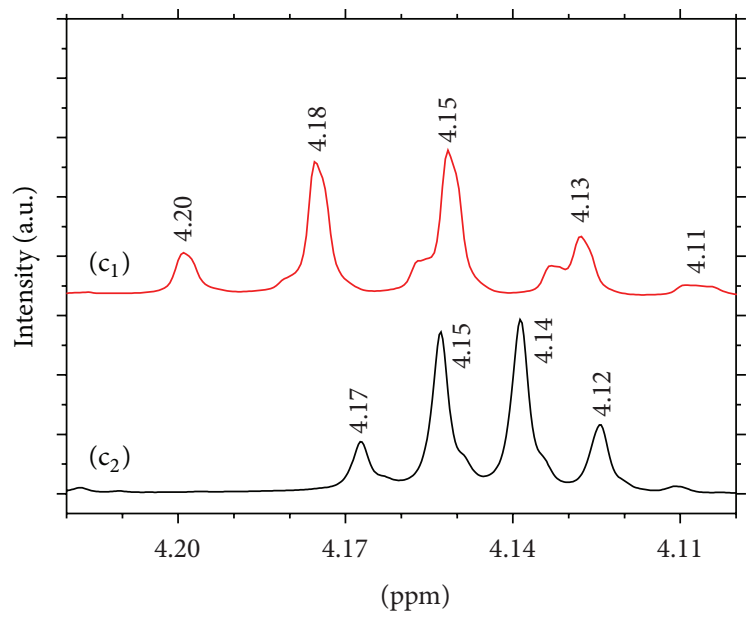

(c)

Figure 6: ${ }^{1} \mathrm{H}$ NMR spectra of $\mathrm{Et}_{2}$ Cit and its complex $\mathrm{CaEt}_{2}$ Cit. $\left(\mathrm{a}_{1}, \mathrm{~b}_{1}\right.$, and $\left.\mathrm{c}_{1}\right)$ are $\mathrm{Et}_{2} \mathrm{Cit} ;\left(\mathrm{a}_{2}, \mathrm{~b}_{2}\right.$, and $\left.\mathrm{c}_{2}\right)$ are CaEt $\mathrm{Cit}_{2}$ (a) Total spectra, (b) $\delta=2.70-3.00$ section, (c) $\delta=4.10-4.21$ section.

and specificity of the two peaks of $2.70 \mathrm{ppm}$ from $3.0 \mathrm{ppm}$. This result indicated that after $1,3-\mathrm{Et}_{2} \mathrm{Cit}$ and $1,5-\mathrm{Et}_{2} \mathrm{Cit}$ coordinated with calcium ions, the property difference of the two formed complexes increased compared with those of the original two ligands.

(3) At $2.70 \mathrm{ppm}$ to $3.0 \mathrm{ppm}$, the $\mathrm{H}$ peaks of $-\mathrm{CH}_{2}$ - shifted from $2.85 \mathrm{ppm}$ to $2.91 \mathrm{ppm}$, and then to $2.81 \mathrm{ppm}$ to $2.94 \mathrm{ppm}$ after $\mathrm{Et}_{2} \mathrm{Cit}$ coordinated with calcium. This finding was due to the $\mathrm{O}$ in $-\mathrm{OCH}_{2}$ that coordinated with $\mathrm{Ca}$, consistent with the IR spectra.

(4) The peak at $\delta=4.0 \mathrm{ppm}$ was assigned to $-\mathrm{OCH}_{2}$ of $-\mathrm{COOCH}_{2} \mathrm{CH}_{3}$ (Figure 6(c)). Compared with $\mathrm{Et}_{2} \mathrm{Cit}$ ( $\delta=4.13 \mathrm{ppm}$ to $4.20 \mathrm{ppm})$, this peak of the complex ( $\delta=4.12 \mathrm{ppm}$ to $4.17 \mathrm{ppm})$ shifted to a high field. This finding indicated the weakening of the induction effect of attracting electrons of $\mathrm{O}$ in $-\mathrm{OCH}_{2}$ from $\mathrm{H}$ after the $\mathrm{O}$ atom in $-\mathrm{OCH}_{2}$ coordinated with $\mathrm{Ca}$. Thus, the total electron density of $\mathrm{H}$ increased, and the absorption peaks moved to a high field.
Elemental analysis, ICP, XRD, FT-IR, and ${ }^{1} \mathrm{H}$ NMR revealed that $\mathrm{Et}_{2}$ Cit formed a $1: 1$ complex with $\mathrm{Ca}^{2+}$, that is, CaEt2Cit.

3.3.5. Coordination Mechanism. The above results showed that $\mathrm{Ca}^{2+}$ was coordinated with $\mathrm{Et}_{2} \mathrm{Cit}$. O in $-\mathrm{COO}$ and $\mathrm{C}-\mathrm{O}-\mathrm{C}$ of $\mathrm{Et}_{2}$ Cit was coordinated with $\mathrm{Ca}^{2+}$ in bidentate ligand. Two kinds of $-\mathrm{OCH}_{2} \mathrm{CH}_{3}$ had different chemical environments in the crystals, that is, $1,3-\mathrm{CaEt}_{2} \mathrm{Cit}$ and 1,5$\mathrm{CaEt}_{2} \mathrm{Cit}$. However, their proportions were still difficult to ascertain because of their similar physical and chemical properties. Based on the above characterization results, two kinds of coordination of $\mathrm{Et}_{2} \mathrm{Cit}$ with $\mathrm{Ca}^{2+}$ are shown in Figure 7.

We rule out the possible coordination of hydroxyl group of $\mathrm{Et}_{2} \mathrm{Cit}$ based on the reason that the FT-IR (Figure 5) and ${ }^{1} \mathrm{H}$ NMR spectra (Figure 6) have confirmed that one of the carbonyl of $\mathrm{Et}_{2} \mathrm{Cit}$ was coordinated with the calcium ion. When one $-\mathrm{COOH}$ and one $-\mathrm{COOCH}_{2} \mathrm{CH}_{3}$ in $\mathrm{Et}_{2} \mathrm{Cit}$ were coordinated with calcium ion, the $-\mathrm{OH}$ group and 


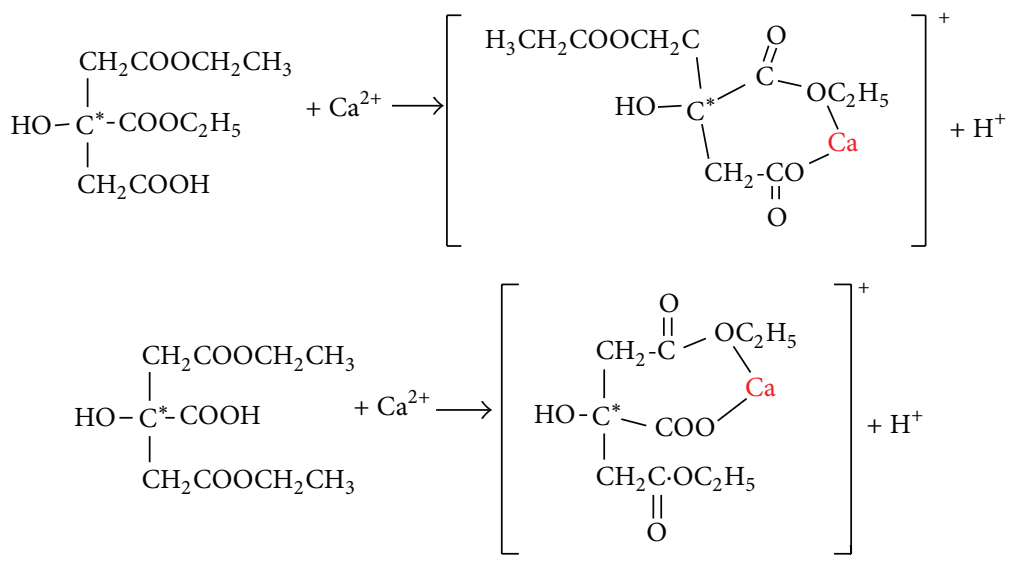

Figure 7: Schematic of the coordination of $\mathrm{Ca}^{2+}$ ion with two isomers of anticoagulant $\mathrm{Et}_{2}$ Cit. The asterisk $*$ shows the center $\mathrm{C}$ atom of $\mathrm{Et}_{2}$ Cit.

the coordinated $\mathrm{Ca}$ ion were separated on opposite sides of the center $\mathrm{C}$ atom of $\mathrm{Et}_{2} \mathrm{Cit}$ (Figure 7); thus - $\mathrm{OH}$ cannot coordinate with calcium ion because of the space steric hindrance.

\section{Conclusion}

The coordination dynamics and effect of $\mathrm{Et}_{2} \mathrm{Cit}$ and $\mathrm{Na}_{3} \mathrm{Cit}$ $\mathrm{pH}$ on $\mathrm{Ca}^{2+}$ in saline water were studied. In $37^{\circ} \mathrm{C}$ saline water, the coordination dynamics equations of $\mathrm{Et}_{2} \mathrm{Cit}$ and $\mathrm{Na}_{3} \mathrm{Cit}$ with $\mathrm{Ca}^{2+}$ were $r=120 a^{2.46}$ and $r=289 a^{2.44}$, respectively. The reverse reaction rate constants $\left(k_{\mathrm{re}}\right.$ 's) of coordination with $\mathrm{CaCl}_{2}$ were 0.52 and $0.15 \mathrm{~L} \cdot \mathrm{mol}^{-1} \cdot \mathrm{s}^{-1}$ for $\mathrm{Et}_{2} \mathrm{Cit}$ and $\mathrm{Na}_{3} \mathrm{Cit}$, respectively. The dissociation rate of $\mathrm{Ca}^{2+}$ of $\mathrm{CaEt}_{2} \mathrm{Cit}$ was faster than that of $\mathrm{CaCit}$. The increased $\mathrm{pH}$ accelerated the dissociation of the complex. With increased $\mathrm{pH}$ from 6.0 to $8.0, k_{\text {re }}$ of $\mathrm{Et}_{2} \mathrm{Cit}-\mathrm{CaCl}_{2}$ increased from 0.04 to 19.80, which was beneficial in improving the anticoagulant effect. $\mathrm{Et}_{2} \mathrm{Cit}$ and $\mathrm{Ca}^{2+}$ were coordinated to form a 1:1 complex, and $\mathrm{O}$ atoms in $-\mathrm{COOH}$ and $\mathrm{C}-\mathrm{O}-\mathrm{C}$ of $\mathrm{Et}_{2}$ Cit were coordinated with $\mathrm{Ca}^{2+}$ in bidentate ligand. $\mathrm{Et}_{2} \mathrm{Cit}$ was able to coordinate with $\mathrm{Ca}^{2+}$, and its release capacity of $\mathrm{Ca}^{2+}$ was stronger than that of $\mathrm{Et}_{2} \mathrm{Cit}$. Thus, it did not require an intravenous infusion of calcium when used as an anticoagulant, thereby avoiding hypocalcemia and hypercalcemia that can be caused by $\mathrm{Na}_{3}$ Cit. Overall, $\mathrm{Et}_{2} \mathrm{Cit}$ was a better anticoagulant than $\mathrm{Na}_{3} \mathrm{Cit}$.

\section{Acknowledgments}

This work was supported by the National Natural Science Foundation of China (30871164) and the Scientific and Technological International Cooperation Project of Xi'an Jiaotong University of China.

\section{References}

[1] Z.-H. Zhang and H. Y. Ni, "Efficacy and safety of regional citrate anticoagulation in critically ill patients undergoing continuous renal replacement therapy," Intensive Care Medicine, vol. 38, no. 1, pp. 20-28, 2012.
[2] B. Szamosfalvi, S. Frinak, and J. Yee, "Automated regional citrate anticoagulation: technological barriers and possible solutions," Blood Purification, vol. 29, no. 2, pp. 204-209, 2010.

[3] N. Patnaik, R. K. Ratho, B. Mishra, A. Chakraborty, and V. K. Sakhuja, "Comparison of ethylenediaminetetraacetic acid and sodium citrate as anticoagulants in collection of samples for cytomegalovirus pp65 antigen detection in renal transplant recipients with suspected cytomegalovirus disease," Journal of Virological Methods, vol. 147, no. 2, pp. 319-321, 2008.

[4] Y.-J. Liao, L. Zhang, and P. Fu, "Simplified regional citrate anticoagulation using a calcium-containing replacement solution for continuous venovenous hemofiltration," Nephrology Dialysis Transplantation, vol. 27, supplement 2, pp. 205-205, 2012.

[5] J. Buturović-Ponikvar, J. Gubenšek, and R. Ponikvar, "Citrate anticoagulation for single-needle hemodialysis: safety and efficacy," Therapeutic Apheresis and Dialysis, vol. 9, no. 3, pp. 237240, 2005.

[6] Y. Ou, J. Han, B. Chen et al., "Synthesis and characterization and anticoagulant properties of diethyl citrate," Asian Journal of Chemistry, vol. 24, no. 11, pp. 4953-4960, 2012.

[7] Z. Chen, B. Chen, X. Yao, B. Gui, Y. Ou, and J. Ouyang, "Anticoagulation of diethyl citrate and its comparison with sodium citrate in an animal model," Blood Purification, vol. 33, no. 1-3, pp. 30-36, 2012.

[8] Y. Ou, B. Chen, H. Peng, B.-S. Gui, X.-Q. Yao, and J.-M. Ouyang, "Thermodynamic features of diethyl citrate calcium complex and factors affecting the complex stability," Asian Journal of Chemistry, vol. 24, no. 10, pp. 4717-4722, 2012.

[9] Q. Tang, L.-M. Zhang, B.-B. Zou, H. Yu, and Y.-L. He, "Local citric acid in vitro anticoagulant, low molecular weight heparin and heparin in high-risk bleeding tendency of the efficacy and safety of the patients underwent hemodialysis," Shanghai Medicine, vol. 30, no. 12, pp. 898-901, 2007.

[10] M. Antonič, J. Gubenšek, J. Buturović-Ponikvar, and R. Ponikvar, "Comparison of citrate anticoagulation during plasma exchange with different replacement solutions," Therapeutic Apheresis and Dialysis, vol. 13, no. 4, pp. 322-326, 2009.

[11] H. M. Oudemans-Van Straaten, R. J. Bosman, M. Koopmans et al., "Citrate anticoagulation for continuous venovenous hemofiltration," Critical Care Medicine, vol. 37, no. 2, pp. 545-552, 2009. 
[12] J. A. Clark, G. Schulman, and T. A. Golper, "Safety and efficacy of regional citrate anticoagulation during 8-hour sustained lowefficiency dialysis," Clinical Journal of the American Society of Nephrology, vol. 3, no. 3, pp. 736-742, 2008.

[13] J. Kozik-Jaromin, V. Nier, U. Heemann, B. Kreymann, and J. Böhler, "Citrate pharmacokinetics and calcium levels during high-flux dialysis with regional citrate anticoagulation," Nephrology Dialysis Transplantation, vol. 24, no. 7, pp. 22442251, 2009.

[14] R. Palsson, K. A. Laliberte, and J. L. Niles, "Choice of replacement solution and anticoagulant in continuous venovenous hemofiltration," Clinical Nephrology, vol. 65, no. 1, pp. 34-42, 2006.

[15] S. Morgera, M. Haase, M. Ruckert et al., "Regional citrate anticoagulation in continuous hemodialysis-acid-base and electrolyte balance at an increased dose of dialysis," Nephron, vol. 101, no. 4, pp. c211-c219, 2005.

[16] H.-U. Meier-Kriesche, J. Gitomer, K. Finkel, and T. DuBose, "Increased total to ionized calcium ratio during continuous venovenous hemodialysis with regional citrate anticoagulation," Critical Care Medicine, vol. 29, no. 4, pp. 748-752, 2001.

[17] K.-N. Fan, Physical Chemistry, Higher Education Press, Beijing, China, 2005.

[18] Y.-S. Yu, "The problems faced by today's peritoneal dialysis and its treatment," Kidney Disease and Dialysis \& Transplantation, vol. 6, no. 11, pp. 555-559, 2002.

[19] A. Schwarzbeck, L. Wagner, H. U. Squarr, and M. Strauch, "Clotting in dialyzers due to low $\mathrm{pH}$ of dialysis fluid," Clinical Nephrology, vol. 7, no. 3, pp. 125-127, 1977.

[20] W.-Y. Sun, Coordination Chemistry, Chemical Industry Press, Beijing, China, 2004. 

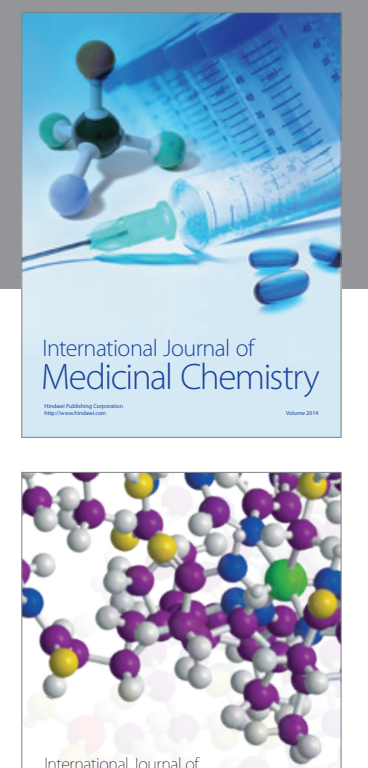

\section{Carbohydrate} Chemistry

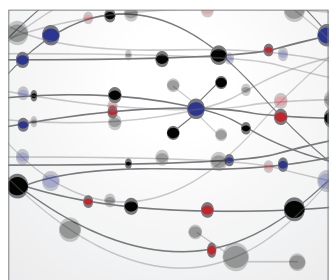

The Scientific World Journal
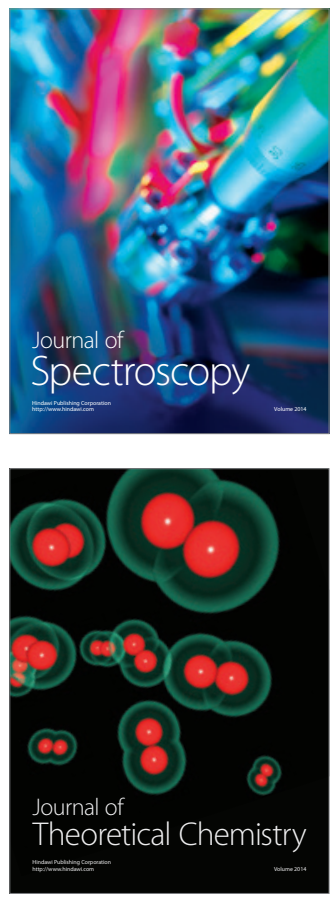
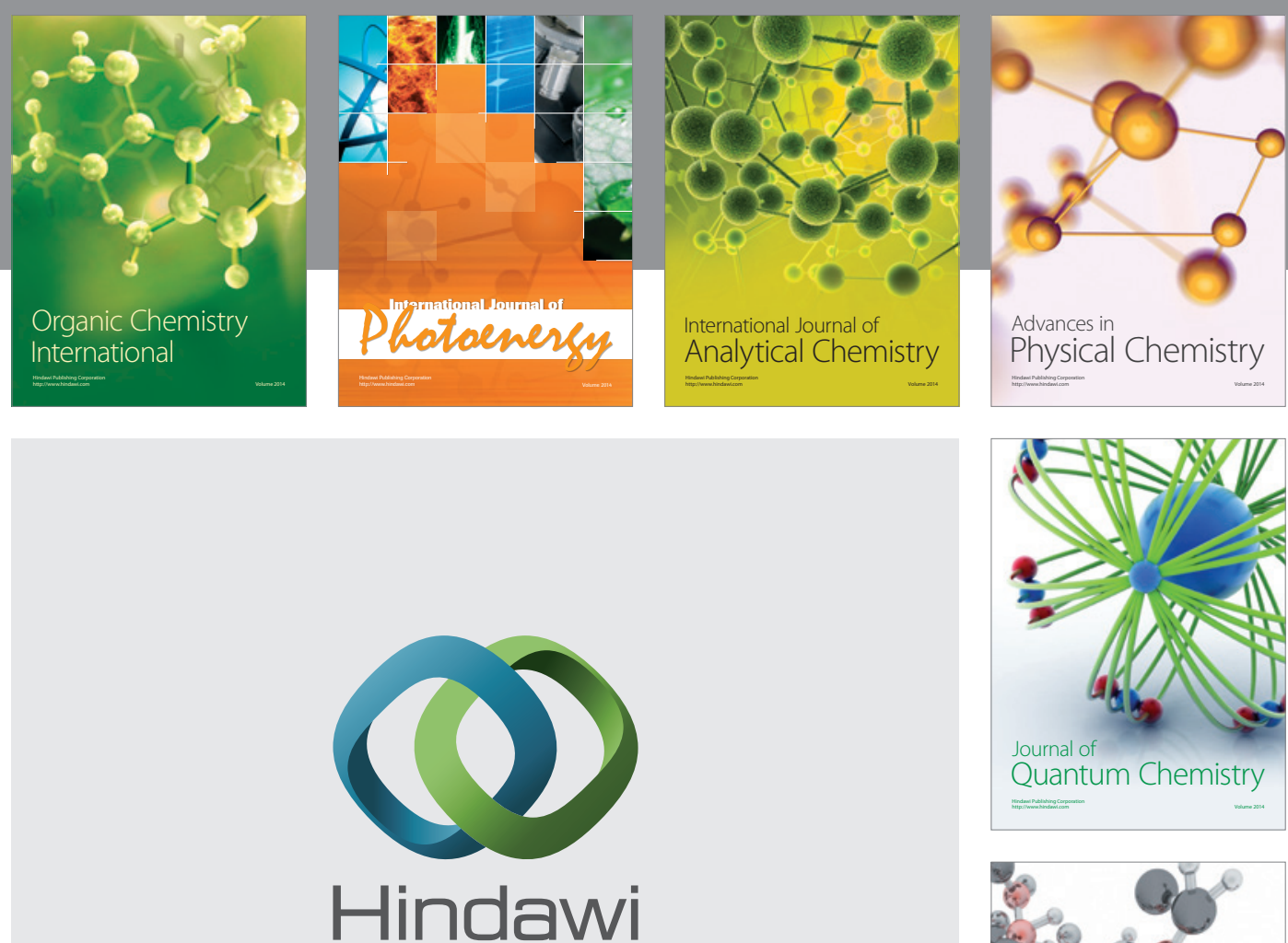

Submit your manuscripts at

http://www.hindawi.com

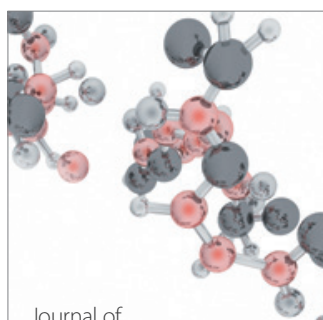

Analytical Methods

in Chemistry

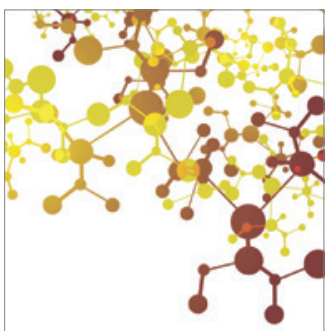

Journal of

Applied Chemistry

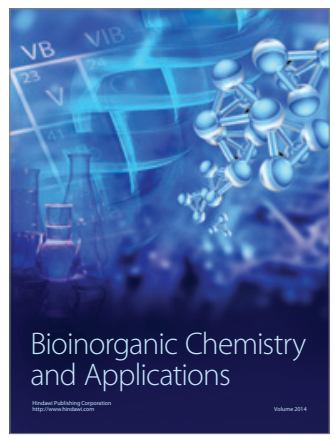

Inorganic Chemistry
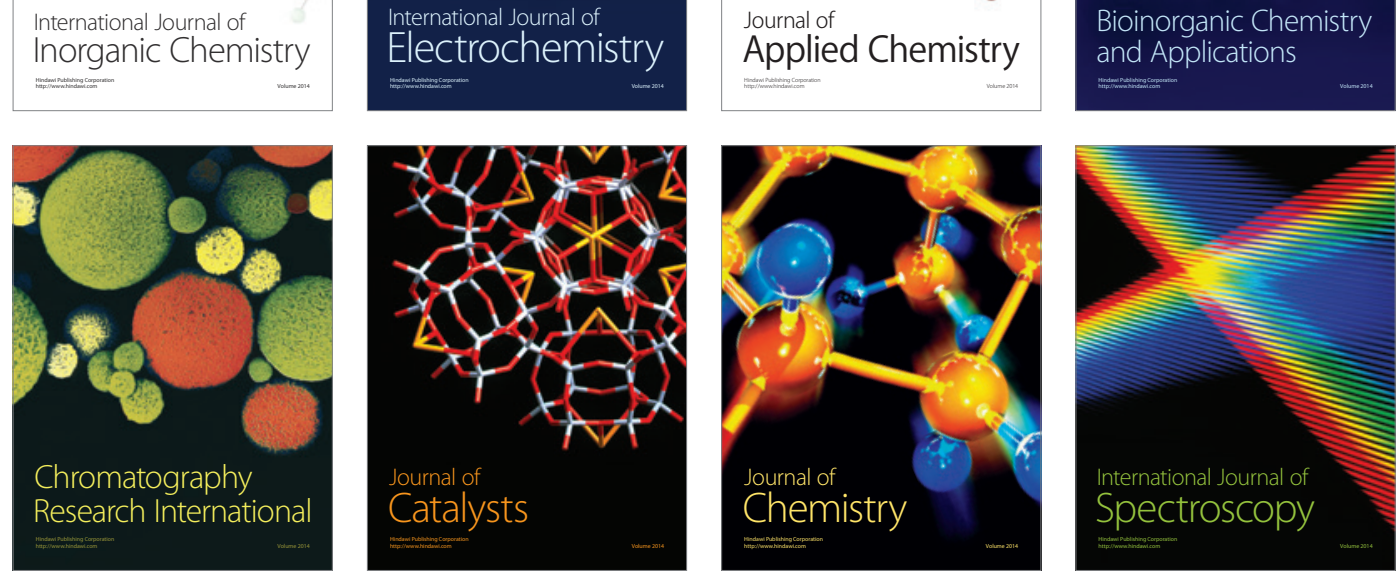